\title{
STUDENTS' EMERGING PEDAGOGICAL REFLEXIVITIES IN RESPECT OF THEIR "STUDENT TEACHERLY BECOMING" ON A PGCE DIVERSITY AND INCLUSIVITY MODULE
}

\author{
J. A. Feldman* \\ e-mail: jennf2103@gmail.com
}

\author{
A. Fataar* \\ e-mail: afataar@sun.ac.za \\ *Department of Education Policy Studies \\ Stellenbosch University \\ Stellenbosch, South Africa
}

\section{ABSTRACT}

Situated in the context of teaching in higher education, the article provides a discussion on how student teachers in a Post Graduate Certificate of Education (PGCE) module mediate their "teacherly becoming" (Fataar 2012) as pre-service teachers. The article presents the argument that learning to become a professional teacher involves not only what the students are learning, but also who they are becoming. The data for the article is drawn from student assignments which invited students to draw on the module readings and class discussions to consider their positioning as intentional/unintentional bearers of the past. The assignment required of them to consider how their emerging reflexivities as student teachers are influenced by their personal and educational backgrounds, and how these affected their "becoming" as student teachers in the PGCE programme. The data is presented and discussed on the basis of four themes that emerged from the student essays. The article concludes by suggesting that modules that prepare student teachers for the complexity of the teaching profession and interaction with their students will be more productive if opportunities are provided in the module's assessment modalities, for the students to reflexively engage with aspects of their "being and becoming" as pre-service teachers. Keywords: higher education, Post Graduate Certificate of Education, pre-service teachers, "teacherly becoming", social justice education, Bourdieu, doxa, doxic assumptions, student selfwritings

\section{INTRODUCTION}

The article is situated within the context of teaching in higher education. It discusses how students in a Post Graduate Certificate of Education (PGCE) programme mediate their "being and becoming" (Barnett 2009) as pre-service teachers. Fataar (2012) describes the intersection 
between how students learn and their acquisition of pedagogical subject content knowledge as they move through a teacher education programme, as their "teacherly becoming". This process, Fataar $(2012,38)$ states, involves the students navigating across "the complex performative space of higher education ... the challenging environments of schools in which they do their teaching practice ... and the space of their lives, rooted in their biographies, which they transact across complex urban and rural spaces". Thus, learning to become a professional teacher involves not only what the student is learning, but also who they are becoming. It involves an "integration of knowing, acting, and being in the form of professional ways of being that unfold over time" (Dall'Alba 2009, 34).

The question that is posed in this article is: How did the content of a Post Graduate Certificate in Education (PGCE) module titled Diversity and Inclusivity, impact on the students' "becoming" as pre-service teachers? We unpack this question by discussing how the knowledge structure or content of the Diversity and Inclusivity module connected with, and impacted on, the students" "being and becoming" in their PGCE year as pre-service teachers.

The data for the article is drawn from student assignments ${ }^{1}$, what we call self-writings, where the students were invited to respond to a question that asked them to reflect on their "positioning as an intentional/unintentional bearer of the past as a core part of [their] dilemmas as a pre-service teacher" (PGCE assignment 2017). This question required the students to draw on the module's readings and class and tutorial discussions to consider how their life trajectories had positioned them in their "becoming" as student teachers during the PGCE module in relation to the content and knowledge structure of the module's focus. The article is based on the centrality of assessment modalities in pedagogical transfer work. We draw on Shalem, Dison and Reed (2013) who foreground assessment from a student and curriculum perspective. They point out that students' academic writing "provide lecturers an opportunity to reflect critically on their assessment practices in relation their course outcomes and pedagogy" (1078). Thinking carefully about the purposes of assignments would allow for their strategic use in facilitating students' intellectual and professional becoming. In the case of the assignment from which we draw the data for this article, formative and development dimensions of assessment are central to the students' emerging reflexivities during the module. The assignment was intended as an opportunity for the students to consider how their pedagogical identities are informed by concepts offered during the module, and, in turn, how they come to think about their early teacherly becoming.

The module Diversity and inclusivity is situated within the Sociology of Education and the students are exposed to readings and discussion on the complex and multiple dynamics that inform racial, class, cultural, linguistics, gender and other patterns of difference and diversity 
in schools. The focus of the module is on providing the students with a conceptual platform for understanding how diversity and inclusion could be engaged and mediated in educational environments based on a framing of social justice. The module uses Fraser's (1997) notion of social justice to invite the students to consider the tension between the redistribution of school knowledge, as for example is currently encoded in the South African Curriculum and Assessment Policy Statement (CAPS), on the one hand, and on the other hand the need to recognise and work with the lifeworld knowledges and social-identity formations of the students. To develop the students' conceptualisation of a social justice framing of education the module includes readings that discuss the dynamics of students' social relations in schools, the formation of student learning identities via their social positioning in schools and a consideration of how student subjectivities are established in their search for quality schooling. The module concludes by providing the students with an introduction to a conceptualisation of more pedagogically just teaching orientation that invites them as pre-service teachers to consider alternatives as to how they, as socially just educators, can engage all their students in their school learning.

Given this specific focus and framing of the module, what this article discusses is how the PGCE students within the Diversity and Inclusivity class were beginning to critically reflect on their "doxic" (Bourdieu 1977) assumptions, based on their socialisation as seen through their personal life histories and experiences growing up in a particular family and community, which had positioned them in particular ways as pre-service teachers. By doxic assumptions we refer to a set of core values and discourses within a social field that are viewed as inherently true and necessary, what Bourdieu refers to as doxa, or what is colloquially taken as the prevailing common discourses about education among pre-service teachers. For Bourdieu however, doxa, or the "doxic attitude" means "bodily submission, unconscious submission" (Bourdieu and Eagleton 1992,121$)$ to conditions that are in fact quite arbitrary and contingent on the social discourses of which they are part, an aspect which we elaborate on further in the article.

The article uses the "self-writings" of PGCE students, who, via their reflective module essays present their analyses of the manner in which the module's content knowledge and class discussions were able to provide an engaging and challenging platform that allowed them to begin considering alternative responses to educational conundrums associated with school going. These alternative responses are responses that might be different to those that had been hitherto informed by their relations within their homes and communities and other educational contexts. Many of the PGCE students, by their own admission in their essay self-writings, grew up in families and communities, attended schools and tertiary institutions on within analogous social and cultural environments. In other words, they exemplified a large degree of cultural 
correspondence. What this means is that many of the students have developed a form of subjective knowledge about society, education and student learning based on the way the knowledge, ideas and objects were structured within the relatively narrow confines of the social and cultural fields that they moved through. In other words, their form of knowledge is subjectively influenced by their personal, intuitive and social connections and relations in their life worlds, and thus the way in which they come to view the world. What the PGCE module aimed to do, therefore, was to challenge or interrupt the students' subjective ways of knowing, in other words their doxa, by providing the students with readings, lecture and tutorial discussions that enabled them to begin to reflexively interact with their own doxic assumptions that had formed over time.

This article starts by situating the discussion within the post-apartheid higher education landscape. Included in this section is an outline of the PGCE module Diversity and Inclusivity that we presented at our previously white Afrikaans university in the Western Cape. We describe the conceptual and theoretical underpinnings of the module as this provides an understanding of the knowledge content that informed the students' reflexive responses to the assignment question posed. An understanding of who the students are within the university context is important in the analysis of their self-writings, and we therefore provide an overview of the students within the PGCE cohort. Following this, the article provides a discussion of the methodology used to analyse the student essays before moving to a presentation and discussion of aspects of the students' self-writings. In this section we provide analytical themes of the student essays and a discussion on how the students begin to reflexively interact with the intellectual content in the module and class and tutorial discussions and how these were beginning to impact on their self-formations and "teacherly becoming" (Fataar 2012) as preservice teachers. The article concludes by suggesting that modules that prepare student teachers for the complexity of the teaching profession and interaction with their students, will be more productive if opportunities in the module's assessment modalities are included which would enable them to reflexively engage with aspects of their "being and becoming" as pre-service teachers.

\section{FRAMING THE DEBATE: KNOWING AND BECOMING OF UNIVERSITY STUDENTS IN POST-APARTHEID SOUTH AFRICA}

In 1994 South Africa ushered in a new democracy based on values of inclusivity and equity, which have imbued much of the country's formal policy-making. The South African democratic government committed itself to an array of transformation-orientated initiatives in the higher education sector that sought to effect institutional change in line with the new South African 
Constitution.

Most of the PGCE students today have not experienced the deep racial divisions associated with the Apartheid era, and as a result are less inclined to check their thinking and attitudes about race and discrimination and their impact on ongoing forms of exclusion. Many of the students define themselves as part of the new democratic South Africa, without critical interrogation as to how they, or their family members, are positioned within the post-apartheid South African landscape. What is often ignored is the way in which aspects of the past, aspects which are often unconsciously formed, or as Jansen (2010) describes it, their "knowledge in the blood", has positioned them within their families and communities. Jansen refers here to the views, beliefs, values and attitudes which young South Africans have acquired from their homes and community contexts which he calls "indirect knowledge" or "inherited knowledge" (Jansen 2010). Jansen argues that university students who were born after 1994, despite being raised and educated in South Africa's new democracy, have inherited a form of "indirect knowledge" from their homes and communities. It is this knowledge which unconsciously informs students' knowledge of themselves and others as an embedded dominant belief system that gives meaning, emotion and authority (Jansen 2010, 60) to how the students think, behave and act.

Jansen's notion of indirect or inherited knowledge can be found as operative in Bourdieu's concept of doxa, habitus and field. Bourdieu describes doxa as a form or discourse and practice of certain beliefs and assumptions that circulate powerfully in everyday settings and constitute an underlying logic that seems more-or-less unquestionable; while habitus refers to a "system of cognitive and motivating structures" or dispositions that function as "principles that generate and organise practices" (Bourdieu 1990, 53) that have been formed over time. According to Bourdieu, a "field of play" can be understood as a structured social space or force field within which interactions, transactions and events occur at a specific time and location (Thomson 2008). A field is not a static entity but fluid and dynamic and particular practices within a field should not only be seen as a product of habitus, but rather as "the product of the relation between the habitus, on the one hand, and the specific contexts or 'fields' within which individuals act, on the other" (Thompson 1991, 14; italics in original). Relating doxa to habitus and field, Bourdieu $(1990,68)$ writes: "Doxa is the relationship of immediate adherence that is established in practice between a habitus and the field to which it is attuned, the pre-verbal taking-forgranted of the world that flows from practical sense". In other words, doxa can be considered as an individual's sense of reality that "causes practices" or makes one's practices seem sensible, or even a social necessity (Bourdieu 1990, 68).

What this means for the PGCE students, is that over time they have become positioned within the logic of particular societal structural formations that have acquired a taken-for- 
grantedness that is perceived as natural for all. Concomitantly, these "positionings" have produced in the students' habitus a form of doxa, a set of beliefs or practices that have become incorporated into their thinking at an almost pre-conscious level, which, unless brought to consciousness and interrogated will continue to inform their "way of being" going forward. Bourdieu states that the habitus is able to be transformed (or added to) by social action and experiences and continues "from restructuring to restructuring" (Bourdieu 1977, 87) or, as Wacquant states, the layering of one's habitus takes place as "any system of transposable schemata that becomes grafted subsequently [onto the habitus], through specialized pedagogical labor".

Developing this, we refer to the students" "learning habitus" as a layer of habitus formation which over time becomes grafted on to their existing habitus. As one's habitus is not a preprogrammed automated response to situations, but rather an internalised unconscious relationship between one's embodied dispositions and a social field (Maton 2008, 51), Bourdieu proposes that in order to critically analyse the basis on which one's habitus has been formed requires an attitude of ongoing reflexivity where we "step back and gain distance from dispositions" (Bourdieu and Wacquant 1992, 136). What Bourdieu is suggesting, is that transformative action by an individual requires a reflexive response that takes into account how one's social and cultural backgrounds, positioned within particular fields and imbued with intellectual and cultural bias, have shaped the way in which one views the social world. For Bourdieu, reflexivity requires individuals to engage with a "systematic exploration of the unthought categories of thought which delimit the thinkable and predetermine the thought" (Bourdieu and Wacquant 1992, 40). This transformation as a form of habitus "layering" we suggest, therefore, occurs as the students begin to reflexively engage with their subjectivity in relation to the module content. Our module attempts to engender a reflexive capacity among the students about the ways their doxa is lodged in their habitus and how it can be shifted over time.

When considering how the PGCE students began the process of reflexivity, we propose that this takes place as an interplay between the students" "learning habitus" (that is the layering of new knowledge through the readings and class discussions) and their doxa, that is their "taken-for-granted" assumptions that hitherto had informed their thinking and practice, which has begun to enable a process that we describe as a "pedagogy of discomfort". By this we refer to the unsettling of the students' "ways of knowing" that had been unconsciously (or without reflection) formed over time given the social spaces they have inhabited.

Disruption of the doxic assumptions that have formed their view of students and schooling in society, we argue, requires a deep and reflexive engagement with their own "ambiguities of 
becoming" (see Dall'Alba 2009). As stated by Thomson $(2004,444)$ who draws on Heidegger,

“... the very way reality shows up for us is filtered through and circumscribed by the stand we take on ourselves, the embodied life-projects which organize our practical activities and so shape the intelligibility of our worlds."

Thus the PGCE student cohort were invited to consider their subjective positionings, via a reflexive consideration of issues of diversity and inclusivity as presented in the knowledge component of the PGCE module.

While certain themes were outlined and discussed within the class, very little further direction was provided for the students who chose this assignment. It was hoped that the students would take up the themes from the module that were pertinent to their personal biographies and life-world contexts and experiences and discuss those which had impacted on their "becoming", their unfolding educational identities, as pre-service teachers.

\section{THE PGCE STUDENT COHORT}

The PGCE student group is a large (190 students) and relatively diverse group in terms of their undergraduate studies, as well as patterns of diversity such as race, class, culture, age, language and gender. Three quarters of the students enrolled are female (approximately 150 students out of 190) while the racial component of the class is 118 white, 66 coloured, 3 Indian and 3 black African students. The class represents a fairly even split between English and Afrikaans with 104 students stating that English is their home language and 86 students stating that their home language is Afrikaans. On the university forms completed for administration purposes, no students give any other language as their home language.

Students enrolling for the PGCE programme are required to have two teaching subjects from their undergraduate degrees in order for them to be accepted into the one-year postgraduate programme that prepares them to become high school teachers in their specialist subject area. The students enter the PGCE from a variety of disciplines, such as Bachelor of Commerce, Science, Arts, Sport Science, Music, Drama and Art to name a few. Some students have also had some work experience either in education (such as teaching English in Korea) or in other work sectors, or have completed their Honours or Masters degrees before deciding to complete their PGCE to qualify to become a teacher. The mix of students in the class invites the potential for engaging and interactive class discussions from a variety of different perspectives.

Due to the size of the class and limited time allocated (the module offers two fifty minute classes per week), students are provided all the module readings beforehand and asked to read 
and engage with the texts before arriving in class. Powerpoint slides are placed before lectures on the university's digital platform, which the students access before the lectures to guide them through the class texts and assist them with their reading of the module texts. At times the classes consist of a more lecture-style explanation of theory or concepts, however, despite the large class format, the students are invited to draw on their previous knowledge and experience to engage in discussion and debate on the educational topics presented in the lectures. The focus of the classes is to challenge the students, via intellectual content, questions and class debate, to develop a set of reflexive responses to the educational problematics that are discussed in the class. Immersed in the way the classes are structured, is an intentional structuring of the type of learning that teachers in schools can engage their learners in, one that invites the learners into in-depth and challenging discussions within the school curriculum content. Thus, the module is based on modelling a pedagogical approach which the pre-service teachers could consider emulating as a means of meaningfully engaging school children in the curriculum content

Included in the structure of the module, are smaller tutorial groups that students can choose to attend. These smaller groups are intended to provide students the opportunity to ask questions, discuss, debate and challenge aspects of the module and module readings in a smaller group setting. It is often in these groups that the students begin to insert themselves and their own biographies into the intellectual component of the module due to the intimacy of the type of discussion that can be facilitated in a smaller group setting. The tutorial classes tend to provide a safe and more personal environment where students are more inclined to share some of their life experiences and make connections between their personal life-worlds and the theoretical and conceptual issues presented in the module readings. These are productive sessions and it has been our experience that the students who make the time to attend and engage in the tutorial groups are more able to reflexively grapple with their personal histories and positions in relation to aspects of the intellectual content of the module.

The module has three assessment opportunities. A test in the first quarter, an assignment in the second quarter and an exam at the end of the year. It was the mid-year assignment where the students were given the option of writing a reflective essay that forms the empirical basis of this article. The self-writings of the students who chose this assignment essay are discursively analysed to provide an understanding of the students' subjective positionings, or pre-service teacher identities, and their self-reflexivity in relation to the responses that the module elicited from them through the intellectual content and the class and tutorial discussions. Using the students' self-writings, the article provides insight into how the students were beginning to think through their own positioning as future teachers within the complexity of education in South Africa. 
The methodology employed in the article involves a discursive analysis of students' essays as a form of student "voice". The essay assignment, invited the students to respond to a question that involved a reflexive engagement between their life histories and experiences within the homes and communities where they grew up, and the intellectual content of the module that is situated in the complex dynamics of diversity and inclusivity within the South African context. This required the students to work with the theoretical and conceptual frameworks and module readings that we provided, and drawing from the class and tutorial discussions, to critically reflect on their positioning as pre-service teachers. The reflective essay was framed as follows:

"It is not the consciousness of man that determines their being, but, on the contrary their social being that determines their consciousness." (Tucker 1978, 4 in Panofsky 2003, 2).

"With reference to the quotation above and drawing on the readings and discussions in the PGCE Diversity and Inclusivity module, write a reflective essay that discusses the educational dilemmas that you experience as a pre-service teacher. You should specifically discuss your positioning as an intentional/unintentional bearer of the past as a core part of your 'becoming' as a pre-service teacher."

Out of the class of approximately 190 students 26 students chose the reflective essay. In the next section, we discuss these essays as a way of understanding how, or in what way, the intellectual content of the Diversity and Inclusivity module intersects with the students' "becoming" as pre-service teachers.

\section{STUDENT SELF-WRITINGS: ANALYSIS AND DISCUSSION}

The student essays, which provide the data for discussion, offer a diverse and rich description of the students' background positioning and personal experiences in terms of which they had developed their personal and educational assumptions and over time. They further provide insight into how, as PGCE students, they were engaging with the module content via the module readings, class discussion and tutorial groups, and how this module's reflexive processes were able to facilitate shifts in their thinking about the their professional as an educator.

The students who form the focus of this analysis and discussion are diverse in terms of aspects of race, class, culture, language and gender. One student, reflecting on aspects of diversity in their essay, states:

\footnotetext{
"One cannot argue that colonisation together with the apartheid government has not left people wounded directly or indirectly. It has left a bitter taste that affects us all whether we pretend not to see it or act towards it. It made us see race, colour, culture and religion before seeing the human being in front of us ... if we do not acknowledge diversity in our schools then we will be teaching our students that they are all the same when in fact we are all different because of who we are, where we come from and what we bring with us to our education. These differences are supposed to be embraced, cherished and recognised." (Emily).
} 
The students presented aspects of their biographies in their essays and describe how their life experiences constructed their educational assumptions, what we refer to as their doxa of education. In other words, their set of beliefs or practices that have formed a taken-for-granted logic or reality over time, has informed their thinking about education and educational practices. Four categories emerged from their self writing essay responses which are tied to their student biographies and how these informed their personal and pedagogical identifications during the module: the first group includes two black African students who completed their undergraduate degrees at a different university, arriving at Stellenbosch for the first time at the start of their PGCE year; the second group was three homosexual white males; the third group was consisted of three Coloured students, and the fourth and largest group was made up of white students. What follows below is a discussion of how each group was positioned in the lecture room and how its learning habitus encountered the module's emphasis on the need for students to reflexively engage in their "teacherly becoming" in diverse educational circumstances.

\section{Wounds from the past: "A bitter taste that affects us all"}

With regard to the first response category, one of the students, Bongiwe, describes herself as a black African from a rural background. She completed her undergraduate studies at a university close to the rural community where she lived as a child. Watching her mother as a factory worker walk long distances in adverse weather conditions made her vow to "make something out of my life, daily wanting so badly to study hard and change my family situation". Bongiwe notes that she attended the village school but always hoped that one day she could attend a former model C school where she could learn to speak, read and write English. The opportunity came during her high school years, but this required that she move from her village and live with her aunt in an urban setting very different to where she had grown up. Her desire for a quality education was greater than the challenges of adapting to the new lifestyle which she describes as "everything was different from the busy streets to the boys by the corner taverns who always made me uncomfortable ... but I had to find a way to fit in without compromising myself, my desire to attend the school was great". Bongiwe completed her high school and obtained marks that allowed her to follow her dream of studying at a university. She completed her undergraduate studies at the University of Fort Hare, obtaining a Bachelor of Science degree in Chemistry. However, once she had completed her studies, she struggled to find a job as she had no computer or access to the internet or transport to go into the city to search for a job. Six months after graduating from university one of the local village high schools where she lived offered her a school governing body post teaching Mathematics. This position opened the door 
for her to apply for other teaching positions and the following year she was offered a permanent position at a private school in the nearby city area. She describes the experience as extremely difficult stating that she,

“... struggled not with the content delivery, but to understand how the school operates, so many things were foreign to me and I had to find a way to fit in ... thanks to today's technology I was able to download movies that were based on private schooling experiences which helped me understand what I needed to do." (Bongiwe).

Bongiwe says that this is how she "fell in love with teaching and I decided to apply to Stellenbosch University to study to become a qualified teacher". She describes the dissonance that she felt between her background and Stellenbosch University on her arrival at the university:

"Everything about Stellenbosch University was different, the culture and the language to a point where I felt that I was too black to be there. I lived in constant panic and fear of not being able to pass. Yes, I was a university graduate but the University of Fort Hare was different, I could relate to the students there, I made friends, spoke my mother tongue to my classmates ... here it was different and some students didn't want to speak English ... people kept asking: 'What made you decide to come and study here?' I felt like people saw me as a person who did not belong here."

Bongiwe's positioning in her PGCE year highlights the vulnerability of students navigating an unfamiliar, cultural dissonant, university environment. She chose to attend Stellenbosch University as she perceived it as being able to provide her with a quality postgraduate education that would enable her to teach in schools that she was unable to access as a child.

In Bongiwe's assignment narrative she describes how she was unprepared for the level of "difference" that she viscerally felt when having to deliver a lesson in English to a group of students who come to Stellenbosch University as part of the micro-teaching educational programme. Each week different PGCE students are allocated lessons to present to a group of school learners who are brought to the university from local schools. One of these schools is an elite school, and it was students from this school to which she was allocated to teach her English lesson. She states that she felt that the students responded differently to her than to her white peers, especially as the learners often asked her to repeat what she said as they were unable to understand her accent. Already feeling like an "outsider to Stellenbosch University", she describes this experience as "one of her nightmares".

The second student, Sandisile, also came to Stellenbosch University for the first time as a post-graduate student. Resonant with Bongiwe's experiences, he states: 
"I attended a disadvantaged school that did not prepare me for what was expected in my PGCE year, especially when delivering a lesson to learners from a private school who, even though I delivered the lesson in English, the learners still kept raising their hands telling me they did not understand what I was saying." (Sandisile).

Bongiwe's reflects on her experiences by drawing on the Diversity and Inclusivity module readings and discusses how the experiences of learners accessing quality schooling in postapartheid South Africa (see Fataar 2015) resonated with her own experiences and determination to move beyond how she feels her life had originally positioned her as a rural, mostly nonEnglish speaking person, destined to follow in the foot-steps of her factory-worker mother. For her, being an unintentional bearer of the past meant that she keenly felt her positioning as a black African from a rural village as a pre-service teacher within the context of Stellenbosch University. In turn, Sandisile wrote that for him the differences in cultural ways of being was the aspect that impacted most on him stating that, "students here are different and thus respect for teachers varies, some students react differently when they are faced with a pre-service teacher". He describes his experience of teaching some school student groups as undermining his confidence in himself during his time at Stellenbosch.

The process of reflection for both students enabled them to consider how to shift their current perceptions of themselves in relation to their experiences during their PGCE year. Bongiwe states:

"We cannot run away from our past and how it has positioned us, but I feel that all the bloodshed, the tears, the hatred that has been going on for years in this country will stay in our veins if we as new teachers do not go out there knowing ourselves or if we hide behind the facts by saying that we do not see colour."

Thus, for Bongiwe and Sandisile, engagement with the Diversity and Inclusivity class concepts and class and tutorial discussions had to turn on finding ways to navigate a different way forward in their "teacherly becoming", a way of moving into the future.

\section{"Hiding in plain sight": Fitting in with the dominant rhetoric of social spaces}

The second group of students who we discuss are three male students. All three of the students identify as gay men. The first student, Calvin, describes himself as a white, Afrikaans, cisgender, homosexual male. He describes his schooling as taking place in a public middleclass school which he describes as a "homophobic space". In comparison to his schooling, completing his undergraduate studies in a small music department Calvin states that his identity as a gay male was considered the "norm" as heterosexual men in this department were both rare 
and even "frowned upon". The open acceptance of his identity as a gay male during his tertiary studies has, according to Calvin, allowed him to drop the façade of heteronormativity and embrace his "queer male identity". What he fears now, as he reflects on his "teacherly becoming" as an educator in the South African school context is "entering a world where my identity and even more so, my views, would be inhibited".

In Calvin's essay he engages with the conceptual and theoretical aspects of the module readings to discuss his "educational becoming" as a gay male within what he describes as a dominant culture or "norm" of heteronormativity that he feels currently exists within South African schools. Using Bourdieu, one of the theorists discussed in the module, Calvin describes heteronormativity as a "doxic attitude" that is manifested "through the symbolic representations that are present in school systems where some are advantaged while others are disadvantaged due to the possession or lack of capital ... or appropriate actions that is in accordance with the rules in the field" (Calvin essay). Citing Samuel (2013, 403), Calvin goes on to state that "Queer or LGBT people experience injustices as their gender and sexuality is excluded and embodies a 'devalued cultural capital'."

Within the Diversity and Inclusivity module, aspects of inclusion and exclusion in relation to learners accessing different school contexts is discussed. Calvin refers to this discussion and relates it to his own feelings of inclusion and exclusion stating:

"Regardless of the legitimacy of the agents who do not have the symbolic capital (victims of symbolic violence), due to the relations in the field, their arguments will not be recognised ... or may be marginalised in a space in order to create a normative behaviour for the space. This would refer to non-heterosexual portrayals in a heteronormative space ... which can easily be seen in the way LGBT or queer bodies are silenced in schools where they are being bullied."

Considering how this impact on his "teacherly becoming" as a pre-service teacher, Calvin notes:

"In a heteronormative school environment I do not have the 'gender capital'. My mannerisms, interests, talents and language usage do not speak of masculinity at all. This could therefore negatively influence my relational positioning in the school. Teachers and learners who have the normative habitus would be able to be positioned above me ... I am conscious of the fact that I would not enjoy the same privileges as my heterosexual counterparts ... such as being able to make reference to my sexuality, my partner or life events as easily and freely as heterosexual teachers could easily do." (Calvin).

Calvin, reflecting on this in his essay notes that he has come to understand how Bourdieu's notion of cultural (symbolic) capital highlights how individuals are able to advance their endeavours when they perform contextually or socially correct behaviour noting that "this would be where heteronormativity or masculinity or the binary view of gender and sexuality is 
awarded" (Calvin essay). Thus, in social structures such as schools, non-heteronormative individuals may experience conflict and could be excluded or marginalised.

Calvin, as do the other two PGCE students who identify as cisgender or homosexual, drew on Bourdieu's concept of habitus to not only understand how their own teaching and identity may be influenced when teaching in a heteronormative schooling system, but also how this has assisted them to understand how other forms of marginalisation position learners in schools.

Referring to the module readings as well as class and tutorial discussions, Alan (a student who identifies as being gay) notes:

"Coming from a relatively conservative white farming background my habitus is comprised of certain aspects - such as respect for one's elders and being courteous ... but also includes aspects which involve treating people differently based on visible and invisible aspects of their identity (race, religion, sexual orientation)."

Reflecting on this, he goes on to state that he has come to realise that teachers easily

"... fall into a set of beliefs that are considered normal, what Bourdieu refers to as doxa that leads to the misrecognition of the forms of cultural capital that learners possess and that can be harnessed in order to aid academic achievement." (Alan).

For the three students who identify as gay, the data from their essays reveal a substantial level of reflexive engagement through their interaction with the module content and class and tutorial discussions by drawing on their own experiences of being marginalised in schools. Calvin notes that due to his experience as a gay male in the schooling system where "LGBT or queer bodies were silenced in schools and bullied" (Calvin), he has begun to challenge his own thinking on how he can find ways to ensure that he does not perpetuate forms of symbolic violence in his own teaching. Alan, similarly notes:

"... I have come to the conclusion that teaching is about vulnerability. Moreover, effective teaching is about being confident in one's vulnerability in order to relate to, and possibly inspire, learners by showing that we are as human as they are and that our academic prowess is something attainable, instead of coming across as mighty glass towers alienating learners from the education process or intimidating them by coming across as (superficially) impervious."

Thus, for these three students, their emerging "learning habitus", as a layer of habitus that is grafted onto their existing habitus through the layering of new knowledge, has taken place in relation to the doxic assumptions that they have experiences as gay men. Their life circumstances have positioned them "uncomfortably" within some social fields and thus they have already experienced a level of disruption in their social worlds. What is seen, therefore, in 
their self-reflective essays is the way in which their interaction in the module readings and discussion provided a productive space as well as theoretical frameworks that enabled them to begin to formulate their emerging "teacherly becoming" in relation to their biographies.

\section{"Being coloured is more a culture than a race"}

The PGCE students in this category identified the communities where they grew up as being characterised by "gangsterism, crime and a place where highly addictive drugs such as heroine and Tik (methamphetamine) are readily available" (Portia). Resisting the deficit positioning of these communities these three students discussed their biographies in relation to living in such communities. They lived in so-called coloured communities but attended schools elsewhere that were perceived to offer a better education. These students, when writing their reflexive essays drew substantially on the work by Fataar (2015). The chapters in Fataar's (2015) book describe, among other aspects, how students in the post-apartheid urban environment mediate racial and cultural differences as they travel across the city to access quality schooling. Fataar's book provided these students with an intellectual platform that enabled them to understand both their own schooling experiences.

One of the PGCE students, who attended primary school in the community but moved to a different high school describes her experience:

\footnotetext{
"At the time I felt greatly privileged to be part of what I believed to be superior schooling. Choosing to gain access to a remoter previously white school, my parents and I were oblivious to the positive and negative consequences of the choice. The change entailed longer school hours as well as longer days travelling to and from school ... These were surface issues in comparison to the fundamental impact on the construction of my identity. My alertness of being in a different environment was immediate due to the fact that I had only known my culture, my colour and my being (my reason for existing). I became acutely aware of my physical presence in the school as it was my first encounter with classmates of other races ... Suddenly I started questioning my intellectual abilities as I realised the standards were much higher than that of my previous school. Not only did I question my intellectual abilities, I also had to suppress my language style, topics of discussion amongst peers and cultural norms that I had taken for granted." (Jody).
}

The student here is describing the way in which discourses and practices operate in social spaces as a norm, or, drawing on Bourdieu, who describes this as the doxa of a field or social space that operates as an underlying logic that dictates on a pre-verbal level, the "rules" of how social interactions take place in that particular field environment. Bourdieu also refers to this as the unwritten "rules of the game". What the student is referring to above, is a realisation that the "rules of the game" that she took for granted in her home and community environment were very different in the school environment which she travelled to each day. She quickly realised 
that learning and adapting to these new "rules" was necessary in order for her to enjoy a relative sense of ease of success in the new school environment.

A second student similarly described her experiences of diversity and inclusivity within the high school she attended:

\begin{abstract}
"The school embraced the changes of desegregation, not by their actions, but through hidden policies filed away behind locked doors. Through this it became apparent that I needed to assemble a new identity on the basis of my interaction between my race, language, culture and social standing and that of the school. Adopting the pre-existing culturally white ethos of the school became my new reality in order to make a success of my schooling career." (Chantel).
\end{abstract}

The three students who identify themselves as "coloured", in their self-writing essays show how they have begun to reflexively draw on their own schooling experiences in relation to the readings and class discussion on diversity and inclusivity and their emerging "teacherly becoming". One of the students concludes her essay by saying:

"With regards to not recognising race (Fataar 2015, 70), I've myself experienced the effects thereof and will place an emphasis on the importance of acknowledging racial and cultural differences in my teaching environment ... I can begin to see how my past has determined my current 'becoming' as a pre-service teacher and I have begun to see direct links between past events in my life and the current ways in which I navigate my pedagogy of teaching ... as such I want to conceptualise teaching as much more than just transferring knowledge to learners." (Jody).

\title{
"Born into democracy, born into the dream of Tata's rainbow nation"
}

The last group of students' self-writings that are discussed, are the students who identify as white middle class students. This forms the largest group of students who completed the reflective essays and is not unexpected given the demographics of the PGCE cohort at Stellenbosch University. In their essays the students describe themselves as the "born-free generation" (Jana), "innocent and free from the mistakes of my white Afrikaans-speaking forefathers - or so I always believed" (Helene). Their narratives situate them in different social spaces in their life trajectories leading up to their PGCE studies at Stellenbosch University, however, central in each of their biographies is their recognition that despite being born post1994, as suggested by Jansen's notion of “inherited” or “indirect” knowledge' suggests, “we all bear a part of our history in the pigmentation of our skin" (Lauren).

The students in this group describe their schooling years as a fairly easy existence admitting that in most instances their "cultural capital ... closely coincided with that of the school" (Alison). By this they refer to an ease of transition from their homes and communities into their schooling where they found that their embodied cultural capital and habitus aligned 
with the requirements of the school system, allowing them access the codes of schooling and consequently relative success in their educational endeavours. The students admit that the decision to study further after completing school was already inscribed in their habitus. One student notes that "my choice to go to university was based on my parents' expectations" (Michaela), while another student states:

"I'm a third generation Matie. My parents and grandparents were in residences during their tertiary education. Before I walked into the residence I was known by the three generation of females that had gone before me." (Katherine).

As Jansen (2010) argues, forms of "indirect knowledge" exist in the students' "knowledge in the blood", "knowledge that has long been routinised in how the second generation see the world and themselves, and how they understand others" $(2010,171)$. It is the knowledge that is embedded in the "emotional, psychic, spiritual, social, economic, political, and psychological lives of a community" (ibid, 171).

Given this ease of privilege, most of these students acknowledge that it was only on arrival at university that they were exposed to ways in which they carried aspects of the past on their physical being; one student notes:

"It was only when I came to university that I really realised how I bear the pain of the past on my skin and in my language. My mere presence at university serves as a reminder of the unfair and discriminatory apartheid years and this hurts a large group of people ... It is here at university where I have been exposed to the severity of how the past impacts on the future by way of my accepted assumptions that I have inherited through my family." (Helene).

Another student states:

"Through the journey of writing this essay I discovered the power of reflection. Reflecting on my own life story, how the experiences of my parents in the greater social context influenced the formation of my habitus. I had to reflect on how I deal with the shame I often experience when thinking of the past and still realising that the very thing I abhor still has power over my way of thinking." (Lauren).

This statement powerfully provides evidence of how doxa, as a form of discourse and practice of certain beliefs and assumptions, continues to influence students' way of thinking and being. This student, in her reflections, drawing on Bourdieu's concept of habitus, further notes:

"The power of habitus in one's life is in its invisibility. When the invisible notions are brought to light, it creates an arena where the 'embodied history internalized as second nature and so forgotten as history ...' (Bourdieu in Panofsky 2003, 13) can be challenged.” (Lauren). 
During the time that this group of students have been at university, the \#feesmustfall student protest movement had erupted on university campus. This movement was a student led protest that began in October 2015 in response to an increase in fees at all South African universities. The protests started at the University of Witwatersrand and spread to other universities across the country. At the heart of the protests was the call for a decolonised free higher education for all students. The protest action at Stellenbosch University, led by a vocal and brave, yet relatively small, student group called Open Stellenbosch, which called attention to the institution's exclusionary institutional culture. Capturing the attention of the university community, Open Stellenbosch played a key role in shifting the university's responses to a myriad of questions including language of instruction, residence culture, sexuality and gender parity. Open Stellenbosch was carefully monitored and contained by the university management, however there were instances of violence and intimidation during the period that the protests were taking place both in October 2015 and again in 2016. One student described a particular incident that took place while she was on her way to class during her final undergraduate year during the \#feesmustfall protests:

"Two students came up to me and started to push me around. They spat in my face and yelled, 'You are a white supremacist and racist. You have privilege and have no idea what we, as people of colour, have been through'. To my shock it was two girls of my residence. That was the moment when I realised that, as an unintentional bearer of the past I am classified according to the colour of my skin and not by my humanity. I am seen as a white person ... who is unaware of their struggle ... my past creates my educational dilemmas." (Nicole).

One student notes how she came to realise the disjunction between how she was taught about the apartheid era in school and university and how her family talked about the past:

"... Over time I have come to realise that the same history that my family talks about with so much pride is based on injustice ... this has led to inner conflict about what my role in society should be as I feel guilty about my history and the privileges I have enjoyed. ... In the module Diversity and Inclusivity I began to make sense of this conflict ... reflecting on this I am finding a way forward where I can accept that my culture and language will always be part of me, but also realizing that my skin, my language and the privilege I have enjoyed is also seen as an injustice by others." (Helene)

A central theme of the essays written by this group of students was their realisation that despite believing that they now lived in the post-1994 "rainbow nation", that as white students they were in actual fact still "carelessly carrying the hurt of discrimination and injustice on my skin" (Helene).

The complexity for the students of becoming aware of how the past has positioned them in relation to their "becoming" as teachers is an important aspect that they navigate during their 
PGCE year. As stated by Dall'Alba $(2013,34)$, learning professional ways of being, what she refers to as the "ambiguities of becoming", involves not only what we know and can do, but also who we are (becoming). The self-writings of this group of students, as white middle class pre-service teachers, show how these students are grappling with aspects of this process in relation to the knowledge dimension of the readings and their "knowing, acting and being". Most of this group of students close their essays by admitting that they are unsure how this awareness, the "knowing" aspect of this process, can translate into practice; "the practical implications are still unknown to me and the challenge lies like a mountain before me". (Katherine).

\section{CONCLUSION}

As pre-service teachers the student self-writings were submitted before the students completed their compulsory twelve week teaching practice in schools. They do not, therefore, show specific evidence of significant change in how they might enact their pedagogy as teachers one day. Rather, what the essays reveal, is how as pre-service teachers their involvement in the class and tutorial discussions of the module Diversity and Inclusivity was beginning to frame their thinking in their "becoming" as teachers. Earlier in this article we referred to the students' "learning habitus" as a form of secondary layering that becomes grafted over time on one's existing habitus. This relates to what Wacquant $(2014,7)$ describes as a secondary layering that takes place "through specialized pedagogical labor". What the article suggests, therefore, is that for the students, the specialised pedagogical labor refers to their reflexive self-writing endeavours that have required them to "step back and gain distance from [their] dispositions" (Bourdieu and Wacquant 1992, 136) in order to reflect on how their social, cultural and educational backgrounds have shaped their view of the social world.

What this article is not claiming, is that the module's knowledge dimension, i.e. its intellectual focus, precipitated significant or transformative changes in the students' normative ways of thinking. While some shifts or changes might have taken place during the course of the module, the key argument of the article is that it was the students' reflexive engagement with the module readings and discussions in relation to their own biographies that supported the potential for the students to begin to shift how they are thinking about themselves in relation to their emerging "teacherly identity". Based on formative assessment meant to facilitate reflexive development, the students' essays were able to illustrate how their doxa of education was being challenged through their involvement in the module discussions and how, in and through this process, secondary habitus layers were being formed that have the potential to impact on, and shift and change, who they were becoming as pre-service teachers within the South African 
educational context. It is from this reflexive platform that the module goes on to concentrate on developing pedagogical approaches that would enable them as student teachers to consider ways in which they can engage the learners they teach in knowledge processes that involve rich and reflexive learning in schools.

\section{NOTE}

1. Ethical clearance was granted by the university (project ID 1704) for the research on which this article is based and the students gave written consent for the use of their essays as data for the article.

\section{REFERENCES}

Barnett, R. 2009. Knowing and becoming in the higher education curriculum Studies in Higher Education 34(4): 429-440.

Bourdieu, P. 1977. Outline of a theory of practice. Cambridge: Cambridge University Press.

Bourdieu, P. 1990. The logic of practice. Stanford: Stanford University Press.

Bourdieu, P. and L. Wacquant. 1992. An invitation to reflexive sociology. Great Britain: Polity Press.

Bourdieu, P. and T. Eagleton. 1992. Doxa and common life. New Left Review 191(1): 111-121.

Dall'Alba, G. 2009. Learning professional ways of being: Ambiguities of becoming. Educational Philosophy and Theory 41: 34-45.

Fataar, A. 2012. Mapping "teacherly becoming" on a teaching practice programme: A reflexive perspective. In Research-led Teacher Education, ed. R. Osman and H. Venkat. Cape Town: Pearson.

Fataar, A. 2015. Engaging schooling subjectivities across post-apartheid urban spaces. Stellenbosch: Sun Media.

Fraser, N. 1997. Justice interruptus: Critical reflections on the "postsocialist" condition. Cambridge: Cambridge University Press.

Jansen, J. 2010. Knowledge in the Blood. Stanford: Stanford University Press.

Maton, K. 2008. Habitus. In Pierre Bourdieu: Key concepts, ed. M. Grenfell. Durham: Acumen Publishing Limited.

Panofsky, C. 2003. The relations to learning and student social class: Toward "re-socializing" sociocultural learning theory. In Vygotsky's educational theory in cultural context, ed. A. Kozulin, B. Gindis, V. Ageyev and A. Miller. Cambridge: Cambridge University Press.

Samuel, C. 2013. Symbolic violence and collective identity: Pierre Bourdieu and the ethics of resistance. Social Movement Studies 12(4): 397-414.

Shalem, Y., L. Dison and Y. Reed. 2013. Towards successful participation in academic writing: What can we learn from assessment? South African Journal of Higher Education 27(5): 1071-1080.

Thomson, I. 2004. Heidegger's perfectionist philosophy of education in Being and Time 37: 439-467.

Thompson, J. 1991. Introduction. In Language and symbolic power. Cambridge: Harvard University Press.

Thomson, P. 2008. Field. In Pierre Bourdieu: Key concepts, ed. M. Grenfell. Durham: Acumen Publishing Limited.

Wacquant, L. 2014. Homines in Extremis: What fighting scholars teach us about Habitus. Body \& Society 20(2): 3-17. 